\title{
ÉTICA EN ACCIÓN: ANTROPOLOGÍA Y HUMANISMO EN LA OBRA DE GEORGE STEINER
}

\author{
Rossana Cassigoli Salamon \\ Universidad Nacional Autónoma de México (UNAM) \\ rossana@correo.unam.mx
}

\begin{abstract}
Resumen / Abstract
Este ensayo se propone esclarecer las herramientas filosóficas que se desprenden del portentoso acervo de George Steiner. Su obra lleva a cabo una lúcida observación y descripción de la formulación y creación lingüística del espíritu humano. Ella no se aparta de la estricta ética heredera del judaísmo espiritual ilustrado. Su legado sobre pensamientos del lenguaje y crítica de la cultura contemporánea (legado paradigmático y de valor heurístico) nos conduce a una reflexión sobre nuestro continente e historia. Como obra antropológica, aspira a la comprensión práctica de lo gregario y a la dilucidación psíquica y fisiológica del fenómeno humano.

Palabras Clave: filosofía de la historia, teoría de la cultura, homo sapiens, metamorfosis, "política de la verdad", judíos, diáspora, exilio.
\end{abstract}

\section{Ethics in ACtION: ANTHRopology AND HUMANISM IN THE WORK OF GEORGE STEINER}

The purpose of this essay is to elucidate the philosophical tools developed in George Steiner's marvelous body of work. In his writings, he carries on a lucid observation and description of human spirit's linguistic creation and formulation. His observations do not deviate from the way of a strict ethics inherited from ilustrated spiritual Judaism. His legacy about thought on language and his role as a contemporary culture's critic (a paradigmatic legacy, of heuristic value) leads us to a reflection on our continent and history. As an anthropological work, it aims at a practical comprehension of gregariousness and to a psychic and physiological elucidation of the human phenomena.

KEY WORDS: philosophy of history, homo sapiens, a theory of culture, metamorphosis, "a policy of truth", jews, diaspora, exile, humanism, hermeneutics, gramar, philology. constante en la escritura de Steiner: "Mi actividad como escritor y profesor, como crítico y académico, ha sido consciente o inconscientemente un in memoriam, una conservación del recuerdo. Pero, ¿acaso podría ser de otro modo tras la Shoah?” 
(Steiner 2000, p. 195). Un lustro antes de su nacimiento, en $1924^{1}$, la familia Steiner dejó la "Viena antisemita" al presentir la proximidad del desastre: "Mi padre vivió la amarga década de 1930 como un hombre atrapado [...] sentía, además, una pena íntima y constante" (Steiner 2000, p. 24).

El fecundo acervo de George Steiner desborda firmeza cualitativa y compone, seguramente, el más abundante acopio de la reflexión cultural del siglo XX. Este escrito desea reproducir, con base en fragmentos de su obra, un itinerario investigativo, un recorrido del intelecto sensible. Poner de relieve, además, ciertos principios cuajados en herramientas hermenéuticas que Steiner nos transfiere. Lo que está en juego en el campo de la reflexión filosófica, afina Steiner, es una "política de la verdad". Tal política es heredera del judaísmo espiritual ilustrado: "Si retrocede ante la pura cacería de la verdad, si la oculta o se aparta de ella, el intelectual traiciona su llamada, está ausente de la mikra (aquello que "se lee" en la Tora). Platón habla del grito del cazador cuando ha acorralado una verdad, incluso cuando esta cacería puede comportar su propia destrucción o la de su comunidad" (Steiner 1997, p. 418).

La observación de una condición judía dispar y mezclada, como la de cualquier otro pueblo, constituye un aporte crítico del pensamiento de Steiner: "A lo largo de milenios, y por la interactiva simbiosis de la emigración, los judíos, como otros pueblos, se han convertido en pueblos mezclados" (2000, p. 118). Nos hace visible la práctica inexistencia de uniformidad cultural, como de unidad histórica en el judaísmo: "Las medidas político-legislativas que aspiran a desenmarañar esta mezcla, a determinar unas fracciones exactas de 'sangre' y parentesco judíos reflejan la locura, el tribalismo inverso y la neurosis del inquisidor español o del matón fascista” (Steiner 2008, p. 118).

No hay, en el pensamiento de Steiner, "judaicidad" que no dependa de la circunstancia histórica. La narración de relatos "ambiguos" y cantares folclóricos, los recitadores, rapsodas, narradores y bardos de la época homérica abundaban en el mundo mediterráneo antiguo entre esas gentes llamadas "judíos". El acto lingüístico más publicado y difundido fue el Antiguo Testamento o Tora. Cristaliza, en la escritura exegética, la producción anónima y plural de un pueblo que emprende un éxodo, una marcha tortuosa hacia una diáspora sin retorno: "El Antiguo Testamento es un registro de motines, de espasmódicos pero repetidos retornos a los viejos dioses a los cuales las manos pueden tocar y la imaginación albergar" (Steiner 1992, p. 59). Las penurias y rebeliones y, a la zaga, el destierro y desbandada de un pueblo emancipado, según Steiner, proveyó un modelo a la historia de Occidente: "El Antiguo Testamento es tan remoto como las estrellas; es asimismo tan prosaico, tan local como un informe cartográfico" (Steiner 2003, p. 19).

Desde tiempos inmemoriales, el diálogo obsesivo del judío con el origen lo ha vuelto, en palabras de Karl Barth, un "enfermo de Dios", o "afligido por Dios". Steiner parafrasea a Kierkegaard para trascender, después, en una reflexión ética: "En esta enfermedad puede ir implícita la supervivencia del hombre en tanto que ser moral,

Francis George Steiner nació en París el 23 de abril de 1929, año característico del empeño por reunificar Alemania y por la aversión hacia los judíos en el ambiente vienés. 
vulnerable" (Steiner 2000, p. 75). Las conversaciones "cara a cara" entre Moisés y Dios plasmadas en el Éxodo - mientras el primero conducía a los judíos desde Egipto a Canaán-son fuentes de una tradición oral milenaria cuya práctica alegórica provoca las sublevaciones populares. La imagen del patriarca hablando con el mismísimo Dios proveyó al pueblo judío de un orgullo de pertenencia y de una fortaleza interior que lo condujo a sublevarse del yugo egipcio. Tal "camaradería con los vientos" precisa para Steiner "la condición histórica, psicológica y moral de los judíos hasta hoy" (Steiner 2003, p. 76).

No obstante, ha reflexionado sombríamente el autor, al canjear su tierra natal "situada en el texto" por otra en Gaza o los Altos del Golán, el judaísmo ha perdido su hogar. Pues el lugar de la verdad es en esencia extraterritorial (Steiner 1997, p. 422). Steiner ha manifestado "su percepción de Israel como milagro indispensable, pero trágicamente marcado por sus contradicciones con respecto al genio ético, universalista, del judaísmo desarraigado". Se ha preguntado continuamente si el significado esencial del judaísmo puede concordar con "las realidades de un estado-nación armado y rodeado de enemigos implacables y cínicos" (Steiner 2000, p. 195). Los vientos de la limpieza étnica, del odio fundamentalista, escribe, soplan también sobre Gaza (Steiner 2000, p. 137). Simultáneamente, Steiner ha perseguido, con paradójica impotencia, la esperanza de que pueda ser recuperado para el judaísmo el fin moral de su vocación (Steiner 2000, p. 196). El sionismo, refrenda, se aparta del ser moral del judaísmo: "Es un defecto lógico del sionismo, un movimiento político laico, invocar una mística teológica-escritural que, en honor a la verdad, no se puede suscribir" (Steiner 2000, p. 76).

Las relaciones de un judío con su identidad pueden ser opacas, tensas y repletas de ambigüedades históricas y psicológicas (Steiner 2008, p. 111). El simple término ‘judío' está erizado por resistentes complicaciones. Es el desmoronamiento y vacío abismal que ocasiona la indefinición primaria entre palabra y objeto, entre nombre y esencia, lo que produce el primer exilio de la existencia humana. El judío -aludido en su condición existencial- vivirá su vida como un esfuerzo desesperado por hallar la manera de regresar a su hogar: "Adorno expuso una máxima profundamente judía según la cual ningún hombre ni mujer que se encuentre como en su casa está en su casa" (Steiner 2008, p. 112). Es, en resumidas cuentas, la distinción entre "destierro" y "expulsión" la que caracteriza el espacio en que transcurre la historia judía (Steiner 2008, p. 112).

En otras palabras, el destierro de sí mismo precede a los destierros territoriales: "El judío puede ser un extraño para sí mismo. Su célebre errar es la representación alegórica-empírica de una búsqueda, de una incesante peregrinación hacia adentro" (Steiner 2008, p. 112). El judío es, observa incisivamente Steiner, ajeno a sí mismo antes que el resto, y este resto, "suele rehuir semejante carencia de hogar, que tiene un aura extraña y enervadora" (Steiner 2008, p. 112). Nos pregunta, por último, en qué libro canónico, que no fuese el Antiguo Testamento, puede encontrarse el mandato "No ames el sueño"?² (Steiner 2008: 112). 
La anomalía de la supervivencia de los judíos, su singularidad irreductible -aún después del exterminio nazi del siglo XX-, es el enigma que persiste golpeando la conciencia prevenida de Steiner. Las prácticas endogámicas y culinarias basadas en dietas arcaicas, y la preservación de un lenguaje litúrgico-legal han sostenido una mínima unidad religiosa en comparación con la secularización inherente a la diáspora. Habida cuenta del costo que han debido pagar, ¿ha valido la pena la supervivencia de los judíos? (Steiner 2000, p. 73). Lo más grave, lo más escandaloso, sería que "los milenios de revelación, de llamamientos al sufrimiento, que la agonía de Abraham y de Isaac, del monte Moriah y de Auschwitz, tuviesen como resultado final la creación de un estado-nación armado hasta los dientes, de una tierra para especuladores y mafiosos como todas las demás. El enigma, la locura de la sobrevivencia debe responder a un llamamiento más elevado. Uno inherente al exilio" (Steiner 2000, p. 76).

Steiner nos da pruebas de erudición lúcida e inteligencia intuitiva ensambladas en juicios flexibles, carentes de exageraciones o "posturas de mandarín". El inventario temático que nos presenta Steiner supone un regreso alegórico al humanismo más clásico; a las fuentes precursoras de una filosofía del "sentido común" (Steiner 2000, p. 36). Las "necesarias sombras amadas" (un encuentro íntimo con los hechos del pasado) le permiten al humanista clásico reubicar la "simiente vital" o la "pauta de la vida". Un clásico, escribe, es "una forma significante que nos 'lee' [...] e interroga cada vez que lo abordamos" (Steiner 2000, p. 32).

El pesaroso tránsito hacia las "posthumanidades", o "subhumanidades", se manifiesta primeramente en lo que Steiner llama una "general retirada de la palabra". Los objetivos del sabio humanista, del "pensador especulativo y solitario, escudriñador de textos y archivos", coinciden poco con la imagen del pedagogo o instructor moderno. La erudición y la filosofía pueden quedar perfectamente fuera de la actividad enseñante (Steiner 2000, p. 61). El problema concierne, preferentemente, al estudio de las humanidades. En los escenarios académicos actuales, las humanidades se han visto acorraladas por la lógica implacable de las restricciones presupuestarías y relegadas por las agendas profesionalizantes.

Desde sus albores judeo-griegos hasta el presente, Occidente había experimentado una fase de "concentrado verbalismo" (Steiner 199, p. 145). Empero, las palabras se han deteriorado "por las falsas esperanzas y mentiras que han proclamado" (Steiner 2000, p. 62). A la postre, la expulsión aciaga de la memorización como herramienta formativa ha vuelto a la propia educación moderna una "amnesia organizada" (Steiner 1992, p. 140). El excesivo celo de las técnicas pedagógicas contemporáneas en contra de la memorización, ha mermado severamente los recursos del adulto. Antaño, los hábitos de enseñanza nacían directamente del uso memorístico: "Muchas cosas se conocían by heart, expresión hermosamente relacionada con lo orgánico, con la presencia interior en el espíritu individual de la significación y el hecho expresado" (Steiner 1992, p. 140). 


\section{El imperativo ético de una "teoría de la cultura"}

Resulta inconcebible una teoría de la cultura, refrenda Steiner, disociada del fenómeno de la barbarie predominante durante el siglo $\mathrm{XX}^{3}$. Toda reflexión derivada del fenómeno de la barbarie, corolario de la frustración de las esperanzas y promesas de la Ilustración, debe permanecer unida a la diagnosis de una "crisis del lenguaje" (Steiner 2000, p. 192). Todavía en el siglo XIX la confianza en la cultura humana entrañaba una actitud orgullosa. Steiner vislumbra las fisuras del "mito del siglo XIX". Para el pensador, el "imaginado jardín de la cultura liberal" " no es sino un lugar idealizado por la desalentadora visión del presente. El propio siglo XIX nutrió la imaginación nostálgica: "Mi tesis sostiene que ciertos orígenes específicos de lo inhumano, de las crisis de nuestro tiempo que nos obligan a redefinir la cultura se hallan en la larga paz del siglo XIX y en el centro mismo de la compleja estructura de la civilización" (Steiner 1992, p. 25).

La ilusoria estabilidad social fue minada en las décadas de 1920 y 1930 . Un "corrosivo ennui" 5 penetraba en la vida social e intelectual europea, "una especie de gas de pantanos, un aburrimiento, un tedio, una densa vacuidad" (Steiner 1992, p. 27). El ilustrativo relato que nos refiere Steiner revela la sombra que se explayaba tras la "larga paz": cuando aparecieron los primeros informes y relatos clandestinos sobre campos de muerte en Polonia, la gente no los creyó. Semejantes atrocidades no podían ocurrir en la Europa civilizada del siglo veinte ${ }^{6}$. Terminaron por secarse "los manantiales de esperanza", acaecimiento que la Ilustración y el siglo XIX no presagiaron, presumiendo un vínculo entre civilización y civilidad (Steiner 1992, p. 106). He aquí la verdadera catástrofe: "Moral y psicológicamente es un hecho terrible nuestra incapacidad de asombro" (Steiner 1992, p. 94).

Permanece la obstinación de Steiner: dilucida la "vasta cuestión" de una "teoría de la cultura" tras enumerar las excesivas pérdidas (humanas, éticas e intelectuales) reflejadas en nuestro actual estado. El perjuicio es difícil de evaluar, como lo es el "inventario de lo irreparable": los "futuros vitales prescindidos", generaciones de "talentos morales e intelectuales" devastados, bajas enormes y "cruelmente selectivas" (Steiner 1992, p. 51). El menoscabo fisiológico de nuestra civilización nos emplaza en

3 Hasta el término "notas" es demasiado ambicioso para designar un ensayo sobre la cultura, en este momento. A lo sumo se puede tratar de precisar ciertas perplejidades. La esperanza puede formar parte de un pequeño ejercicio (Steiner 2000, p. 107).

4 "Nuestra sensibilidad sitúa ese jardín en Inglaterra y en la Europa Occidental entre alrededor de la década de 1820 y 1915" (Steiner 1992, p. 19).

5 "El empleo que hace Baudelaire de la voz spleen es el que más se aproxima al concepto: spleen expresa la combinación, la simultaneidad de un exasperado, vago esperar - pero ¿esperar qué?-y de un grisáceo desfallecimiento" (Steiner 1992, p. 25).

6 Para ampliar este tema: Primo Levi, "Cartas de alemanes", Los hundidos y los salvados, 1989. 
una lúgubre "utopía tecnocrática e higiénica que funciona en un vacío de posibilidades humanas" (Steiner 1992, p. 96).

Los acontecimientos irreparables se resumen en el abandono de la moraleja del progreso histórico: "La imagen que llevamos en nuestro interior de una coherencia perdida, de un centro rector, tiene mayor autoridad que la verdad histórica" (Steiner 1992, p. 24). La conciencia contemporánea ha introyectado la carencia del humanismo en relación con la acción social. Una evidencia de ello comparece como la más radical derrota humana. Es prueba palmaria de lo que Steiner llama una "cultura disminuida" en la "adormecida prodigalidad de nuestra familiaridad con el horror" (Steiner 1992, pp. 70-76).

Steiner persigue desentrañar las "relaciones internas entre las estructuras de lo inhumano y la matriz contemporánea de una elevada civilización" (Steiner 1992, p. 48). El índice de cambio social no tiene precedentes; revela transformaciones del orden cualitativo y su primera expresión se anuncia en la "situación local" de una civilización elevada. Tal civilización gozaba, en tiempos recién pasados, del irrebatible señorío occidental prevaleciente durante dos milenios. Los centros evidentes del ímpetu filosófico, científico y poético, de matriz anglosajona, prosperaron en la cuenca del Mediterráneo y norte de Europa: "No se ignoraba las creaciones intelectuales de otros países; el oriente y el Islam impresionaron la sensibilidad europea, pero en ningún caso existía un sentimiento de genuina paridad” “№ es la noción misma de cultura sinónimo de elitismo?" (Steiner 1992, p. 86).

Se perdió, en resumidas cuentas, la "utopía ontológica, el impulso original y la capacidad metafísica y técnica de "soñar hacia delante" (Steiner 1992, p. 97). Que no se experimente ya la historia como curva ascendente conduce a debatir íntegramente la procedencia del modelo historiográfico lineal y a concebir la posibilidad teórica y práctica de su interrupción. Sin dejar de considerar la incertidumbre que rodea, -en las filosofías prácticas- la prefiguración de un modelo civilizatorio sustituto. Sin dejar de razonar, tampoco, la disolución de los axiomas históricos y desgaste de la idea del hombre como propósito y proyecto. La sensibilidad y la inteligencia "se han expandido en una zona neutral", en la cual, y esta es la verdadera catástrofe, las fuerzas culturales innovadoras sufren "sorprendentemente poco": "Aquellos para quienes un gran poema, un pensamiento filosófico, un teorema son en definitiva de supremo valor, ¿no ayudan acaso a los que arrojan NAPALM mirando hacia otra parte y adoptando una posición de “tristeza objetiva' o de relativismo histórico?” (Steiner 1992, p. 104).

Se ha señalado insistentemente que el fin de un sistema jerárquico de valores funda el hecho primordial de nuestra actual circunstancia intelectual y social. Steiner nos ofrece evidencias: la "expansión numérica" de la educación ha sido limitadamente asistencialista, pero completamente alejada de la excelencia formativa. Desastrosa en el propósito de materializar lo que llama una "coherencia política superior". Es aterrador que los frutos del intelecto académico hayan acompañado al "nuevo pesimismo estoico e irónico", factor determinante de la "postcultura" (Steiner 1992, p. 108).

Las realizaciones técnicas han trastornado las estructuras básicas de la vida privada y colectiva. Advienen revoluciones de la conciencia que prefiguran, antropológicamente, una nueva tipología del hombre. No poseemos, declara Steiner, un vocabulario exacto 
para designar "metamorfosis psicosociales o socio fisiológicas"; no obstante, dichas metamorfosis constituyen la diferencia más significativa de la "postcultura" (Steiner 1992, p. 113) Nos emplaza de cara a una pregunta antropológica universal: ¿está la especie humana mostrando síntomas de un cambio en sus estructuras mentales, de una suerte de transformación orgánica de la conciencia? Si tal mutación universal existiese, ¿refleja mutaciones orgánicas demostrables? (Steiner 1992, p. 113).

Empero, la biosociología y la genética histórica son aún demasiado generales en sus esquemas conceptuales para dar cuenta de la indudable metamorfosis ${ }^{7}$. La antropología de Steiner, es preciso reiterar, apunta a considerar la destrucción de las "formas internas de la cultura" (patrones de reproducción y transmisión de las prácticas culturales) en un contexto de grandes limitaciones de la biosociología y la genética histórica. Son las funciones y la propia concepción instrumental las que no marchan.

La visión filosófica de Steiner procede de una calamitosa ruina de las posibilidades humanas: "Queda mucho por explicar del horroroso enigma". Paradójicamente, no es posible idear un modelo de cultura, que rescate a la humanidad de tal ruina, desprovisto de un núcleo utópico (Steiner 1992, p. 98). La sustancia vital de una teoría de la cultura, piensa Steiner, es de naturaleza religiosa en el sentido antiguo: "En el análisis definitivo, es lo teológico y lo metafísico lo que configura la trágica complicación de los hechos" (Steiner 1992, p. 121).

La huella palpable de la filosofía es la aclaración, la "limpieza a fondo del desván de la mente". Emprendemos un viaje interior del cual retornamos transfigurados; ya nunca seremos los mismos. El descenso al ignoto torrente íntimo será inquietante y desgarrador. Empero, si en nosotros existe la apertura hacia la contingencia y late el propósito de fructificar "estos cambios de audición, visión, cognición, estas nuevas incursiones en el recuerdo, se traducirán en acción; praxis. Cambiar la vida: dilema teológico par excellence" (Steiner 2000, p. 40).

\section{El dramatis persona}

Un manual de heráldica, fascinante obsequio recibído en la infancia, le reveló a Steiner la innumerable especificidad, minuciosidad y amplísima diversidad de las sustancias y formas del mundo. El detalle podría no tener fin. Nunca, ningún inventario podría ser completo. Relata: “Crecí poseído por la intuición de lo particular” (Steiner 2000, p. 15). La fascinación y temor de la unicidad inconmensurable, la ausencia de repetición, ha preocupado al pensamiento filosófico desde Heráclito: "la sensibilidad clásica griega se acobardaba ante los números irracionales y lo inconmensurable" (Steiner 2000, p. 17).

Lo que se sabe sobre la "escala temporal evolutiva", nos ilustra Steiner, hace en alto grado improbable que se estén produciendo cambios psicofisiológicos a un ritmo dramático observable. 
Steiner afirma, con voluntad impertérrita, la creencia en la fuerza motriz de la individuación y la desconfianza en la teoría. El concepto de "teoría", explica, implica necesariamente experimentos y falsificaciones cruciales, "auténticas maravillas de improbabilidad" (Steiner 2000, p. 127). Particularmente, la invocación de la teoría en el terreno de las humanidades, en la historia y los asuntos sociales, en la literatura y las artes, le parece resueltamente "mendaz". El prestigio académico del cual goza la teoría en las ciencias sociales y humanas, surge del lamentable empeño de encontrar regularidades en el "movimiento del espíritu", expresión que atribuye a Dante.

Parece refrendar una verdad palmaria: en las humanidades -no susceptibles de experimentos irrefutables ni de comprobación- la teoría no es más que "intuición impaciente": "En la dinámica de la semántica, en el flujo de lo significativo, en la libre interacción de interpretaciones, las únicas proposiciones son una opción personal" (Steiner 2000, p. 18). El esquema abstracto no es capaz de sustanciar la circunstancia existencial temporal, familiar y psicológica del dramatis persona (Steiner 2000, p. 18).

\section{Homo sapiens, "invitado de la vida"}

Es posible que el judío de la diáspora sobreviva para ser un invitado entre los demás hombres. Un invitado que accede a las costumbres y leyes de sus anfitriones, pero que trabaja en enmendarlas (Steiner 2008, p. 141). Es un modo de sugerir a nuestros semejantes que todos los seres humanos deben aprender a vivir unos y otros como "invitados de la vida". Todos somos invitados de la vida, profiere Steiner, y hemos resultado ser comensales vandálicos: "Mamíferos capaces de alcanzar elevados niveles de comprensión y creatividad ética, aunque persistentemente territoriales, agresivos hacia sus rivales, proclives al contagio del odio colectivo, a los reflejos homicidas del rebaño, son llamados a idear instituciones de civismo, de autocontrol y colaboración altruista en la polis, en la multitudinaria "ciudad de los hombres"' (Steiner 2000, p. 141).

El arte de ser un invitado es, a menudo, casi imposible de cultivar. Manifiesta Steiner: "Hemos convertido en un vertedero de residuos tóxicos este entorno de extraña belleza". Además, los prejuicios, la envidia, y los atavismos territoriales por parte del anfitrión, plantean una constante amenaza. La vocación de "invitado" encarna una aspiración mesiánica; "la función de ser insomnes y causar irritación moral al resto de los hombres se me antoja como el mayor de los honores" (Steiner 2000, p. 85).

El célebre pasaje infantil que refiere Steiner, en el magnífico Errata-acerca de la lectura de la Ilíada alentada por el padre-confirma esta percepción de la condición de "invitados" que ostentan los seres humanos en el espacio del universo. El padre escoge el canto XXI: "Enloquecido por la muerte de su adorado Patroclo, Aquiles aniquila a los troyanos, que se baten en retirada. Nada puede detener su furia homicida [...]. El malvado Licaón acaba de regresar de Lemnos, para ayudar a la defensa de la ciudad de su padre. Poco antes Aquiles lo había capturado y vendido como esclavo en Lemnos, poniéndolo así de forma irónica a salvo" (Steiner 2000, p. 27). 
Steiner reclama nuestra atención sobre el "fatal intercambio" entre el joven Licaón y Aquiles. Licaón suplica a Aquiles que le perdone la vida. Es preciso descubrir el sentido de la respuesta de Aquiles, antes de que éste proceda a inmolar a Licaón: “Aquiles es el lúcido instrumento de la extinción que habita la vida [...] todos le debemos a Dios una vida, es la afirmación de Aquiles [...] todos le debemos a la muerte una vida" (Steiner 2000, p. 30). Nace así una terrible claridad. Aquiles realiza un enigmático acto de perdón: cuando se enfrenta a una realidad difícilmente soportable, el hombre perdona a la vida, "perdona a la condición humana ser esa cosa mediocre y finita" (Steiner 2000, p. 30). Aprender de memoria el relato paterno equivalió a adquirir una "guillotina contra la ilusión" y la comprensión de que "la mañana, la tarde o la noche de nuestra muerte están ya escritas” (Steiner 2000, p. 41).

\section{La esperanza es gramática}

Que nuestra condición biológica y nuestra condición semántica están intrínsecamente unidas es el presupuesto explícito del razonamiento de Steiner. La multiplicidad de lenguas entraña una bendición y un júbilo. A corta distancia del "privilegio del políglota", (Steiner 1998, p. 118) el ciudadano monóglota se ha "purificado" de su pasado inmigrante, domesticación que supone un empobrecimiento del espíritu humano. Responde sin embargo a un trauma inmemorial: el incidente de Babel" (Steiner 1998, p. 108). La leyenda de Babel en la Tora nos ilustra, es una de las más enigmáticas y fragmentarias; insinúa una hýbris. El homo sapiens-sapiens no habla una sola lengua veraz y funcional, sino que un "balbuceo maldito infecta sus trabajos y sus días" (Steiner 1998, p. 109).

En su atributo inmortal el alma se ilustró de todas las cosas en un estado previo a su existencia. Y dado que todas las cosas están correspondidas, es posible captar los componentes del conocimiento mediante contigüidad y asociación. El aforismo de que "conocer es recordar" se atribuye a la voz de Sócrates. Platón y Aristóteles heredaron este precepto -de origen judeo-helénico- presente, así mismo, en la Tora $^{8}$. El maestro es quien provoca las visiones que son re-visiones (Steiner 2004, p. 37); recuperación de un conocimiento latente y recóndito al interior de cada uno: "No es posible hacer justicia en una breve panorámica a la sutileza dialéctica, los recursos intelectuales, la ironía, el humor, el patetismo y en ocasiones la explosiva alegría-cuando el alma danza con los materiales conservados, aunque el mundo que denotan sea ceniza" (Steiner 2004, p. 145).

La gramática corresponde, según Steiner, al núcleo del pensamiento: "La esperanza es investida de poder por la sintaxis" (Steiner 2008: 82). Su historia pertenece a las tensiones dialécticas producidas entre la herencia y la innovación, entre la corrección y

$8 \quad$ Nacer es olvidar; conocer es recordar. El Talmud (Tratado Niddah, 30 b) dice que el feto humano conoce toda la Tora. En el momento de nacer, sin embargo, un ángel le toca la boca y el recién nacido olvida. Deberá volver a aprender la Tora. 
la subversión (Steiner 2000, p. 34). El acto de la traducción, o acto de desplazamiento del significado, es la trama que ha ocupado por entero la actividad intelectual de Steiner. Nunca será nítido el trato entre la tradición como lo "entregado o recibído" y la forma en que invocamos esa herencia. La traducción es una "ética en acción, fruto de la cosecha de Babel" (Steiner 2000, p. 133).

Pese a su carácter oscuro, bretes, peligros y aporías, la traducción es, pese a todo, exclama Steiner, el "oxígeno" de las comunidades con lenguas minoritarias y tradiciones no reconocidas 9 . Una "selección antinatural" ha suprimido las lenguas numéricamente pequeñas y pragmáticamente débiles. Ellas han sido barridas como la flora y la fauna de grandes regiones de la tierra. Es indudable la pérdida irremediable y disminución de oportunidades del hombre cuando muere una lengua. Con ella perece no solo el linaje vital de un idioma, sino la figuración de un futuro posible, "drástico empobrecimiento en la ecología de la psique humana" (Steiner 2008, p. 82). Cada día, escribe insistentemente, el número de fórmulas para decir "esperanza" disminuye: "La esperanza es gramática" (Steiner 2000, p. 133).

La ética practica una literal y metafórica filología. Las raíces de las palabras y los signos llegan hasta el corazón de las cosas: el propio vocablo "filología" contiene amor y logos. Tras ella pero inseparable de ella, llega la "responsabilidad". Hay tantos modos de respuesta como de interpretación (Steiner 2000, p. 36). La ética, por antonomasia, comparte frontera con la hermenéutica, arte de la interpretación y del espíritu (Pomian 1997, p. 99).

\section{La relación propia del hombre con la verdad}

El profundo judaísmo paterno le transfirió a Steiner la vocación del enseñante, mandatado a transmitir la verdad: "Yo no era capaz de concebir el propósito que animaba el plan de mi padre. Aceptaba con ánimo incondicional la idea de que el estudio y el ansia de conocimiento eran los más naturales y definidos ideales. Mi infancia se convirtió en un festival de exigencias" (Steiner 1998, p. 26).

Ya en la época de la Atenas clásica, nos instruye Steiner, prevalecía la certeza de que la indagación intelectual constituye un movimiento natural; que la relación propia del hombre con la verdad es la relación del "perseguidor" (Steiner 1992, p. 174). El carácter inquisitivo, el mandato de perseguir los hechos, está impreso en la "estructura misma electroquímica" de la corteza cerebral de nuestra especie (Steiner 1992, p. 173). La verdadera cuestión es esclarecer si corresponde desplegar ciertas líneas de averiguación. ¿Qué sucedería, se interroga Steiner, si la siguiente puerta

$9 \quad$ Por una parte, descubre que el significado emerge como el más problemático de los conceptos filosóficos - Babel insinúa una hýbris-y, por otra, que la empresa de la traducción debe desagraviar "por su incursión, por su rapacería y lucro" (Steiner 2000, p. 130). 
nos abriera a realidades "ontológicamente opuestas a nuestra cordura y limitadas reservas morales"? ¿Tenemos, acaso, "la libertad de seguir pistas neuroquímicas o psicofisiológicas relativas a las formas parcialmente arcaicas de la corteza cerebral, si semejante exploración nos conduce al descubrimiento de que los odios étnicos, la necesidad de la guerra y los impulsos auto destructivos aludidos por Freud son hechos heredados? (Steiner 2000, p. 175).

Pese a todo, Steiner reflexiona, “Cómo renunciar al pensamiento y a la trascendencia, al lenguaje que con sus futuros verbales nos permite la esperanza?" Podemos, cuando nos place, negar, reconstruir, alterar el pasado, el presente y el futuro. Podemos también 'cartografiar' de otro modo los factores determinantes de la realidad pragmática, y así mismo, encontrar un sentido a la existencia.

\section{Referencias bibliográficas}

Levi, Primo (1989), “Cartas de alemanes”, Los hundidos y los salvados. Barcelona: Muchnik Editores.

Pomian, Krzysztof (1997), "Historia cultural, historia de los semióforos", en JeanPierr Rioux y Jean-Francois Sirinelli, Para una historia cultural. México: Taurus.

Steiner, George (1992), En el castillo de Barba Azul. España: Gedisa. Siruela. (1997), "El texto, tierra de nuestro hogar", Pasión intacta. Madrid: (1999), Heidegger. México: Fondo de Cultura Económica. (2000), Errata. España: Siruela. (2003), Prefacio a la Biblia hebrea. Madrid: Siruela. (2004), Lecciones de los maestros. México: Fondo de Cultura Económica (2008), Los libros que no he escrito. México: Fondo de Cultura Económica. 